\title{
Erratum to: Identification of quantitative trait loci for panicle length and yield related traits under different water and $P$ application conditions in tropical region in rice (Oryza sativa L.)
}

\author{
Ian Paul Navea - Maria Stefanie Dwiyanti · Jonghwa Park · \\ Backki Kim • Sangbum Lee • Xing Huang • Hee-Jong Koh • \\ Joong Hyoun Chin
}

Published online: 31 January 2017

(C) Springer Science+Business Media Dordrecht 2017

Erratum to: Euphytica (2017) 213:37

DOI 10.1007/s10681-016-1822-z

Due to an unfortunate turn of events, the name of the fourth author appeared incorrectly in the original publication and should have read Backki Kim.

The correct representation of the authors' names is listed here and should be treated as definitive.

The online version of the original article can be found under doi:10.1007/s10681-016-1822-z.

I. P. Navea - M. S. Dwiyanti

Plant Breeding, Genetics, and Biotechnology Division, International Rice Research Institute, Los Banos,

Philippines

J. Park · B. Kim · S. Lee · X. Huang · H.-J. Koh ( $\square)$ Division of Plant Science, Plant Genomics and Breeding Institute, and Research Institute of Agriculture and Life Sciences, Seoul National University, Seoul 08826, Korea e-mail: heejkoh@snu.ac.kr

\section{J. H. Chin $(\bowtie)$}

Graduate School of Integrated Bioindustry, Sejong

University, Seoul 05006, Korea

e-mail: jhchin@sejong.ac.kr 